\title{
Enhance the accuracy of control algorithm for multilevel inverter based on artificial neural network
}

\author{
Mohammed Rasheed, Moataz M.A. Alakkad, Rosli Omar, Marizan Sulaiman, \\ Wahidah Abd Halim \\ Universiti Teknikal Malaysia Melaka, Faculty of Electrical Engineering, Industrial Power, Malaysia
}

\begin{tabular}{l}
\hline Article Info \\
\hline Article history: \\
Received Apr 1, 2020 \\
Revised May 19, 2020 \\
Accepted Jul 20, 2020
\end{tabular}

Keywords:

Harmonics

Artificial intelligence

Modified multilevel

Inverters

Five level

\begin{abstract}
In converters or multilevel inverters it is very important to ensure that the output of the multilevel inverters waveforms in term of the voltage or current of the waveforms is smooth and without distortion. The artificial neural network (ANN) technique to obtaining proper switching angles sequences for a uniform step asymmetrical modified multilevel inverter by eliminating specified higher-order harmonics while maintaining the required fundamental voltage and current waveform. However, through this paper a modified CHB-MLI are proposed using artificial intelligence optimization technique based on modulation selective harmonic elimination (SHE-PWM). A most powerful modulation technique that used to minimize a harmonic contants during the outout waveform of multilevel inverter is a SHE-PWM method. The proposed a five-level modified cascaded H-bridge multilevel inverter (M-CHBMI) with ANN controller to improve the output voltage and current performance and achieve a lower total harmonic distortion (THD). The main aims of this paper cover design, modeling, prediction for real-time generation of optimal switching angles in a single-phase topology of modified five level CHB-MLI. Due to the heavy cost of computation to solving transcendental nonlinear equations with specified number, a real-time application of selective harmonic elimination-pulse width modulation (SHEPWM) technique is limited. SHE equations known as a transcendental nonlinear equation that contain trigonometric functions. The prototype of a 5level inverter in digital signal processing (DSP) TMS320F2812 reveals that the proposed method is highly efficient for harmonic reduction in modified multilevel inverter.
\end{abstract}

Copyright $@ 2020$ Institute of Advanced Engineering and Science. All rights reserved.

\section{Corresponding Author:}

Mohammed Rasheed,

Universiti Teknikal Malaysia Melaka, Faculty of Electrical Engineering, Industrial Power,

76100 Hang Tuah Jaya, Durian Tunggal, Melaka, Malaysia.

Email: rasheed@utem.edu.my

\section{INTRODUCTION}

The switching semiconductor devices with high power handling capability real-time multilevel power conversion has become a rapidly growing area of power electronics with good potential for further development. In multilevel inverter can be generate Ac voltage based on Dc source from PV, winding and battery application. The multilevel inverter has three advantage, converted Dc to Ac voltage, reduce total harmonic distortion (THD) and less number of switches component [1,2]. In multilevel inverter have been three type of topologies clamped capacitor (DC) flying capacitor (FC) cascaded H-bridge (CHB) [3]. The structure of multilevel inverter for consist eight switching drive can be generated five level inverters. Therefore, increase number of switching PWM leads to increase output voltage level and then leads to high cost for circuit [4]. However, the multilevel inverter has limitation harmonic order in 7-level 3th, 5th by using optimization technique are PSO, NR and GA algorithms are present in [5]. In nine level multilevel inverter 
with phase disposition (PD) PWM scheme can be generated waveform voltage based on transistor clamped H-Bridge multilevel inverter (TCHB), with Dc supply equal $500 \mathrm{~V}$ signal frequency is $50 \mathrm{~Hz}$, modulation index and currier frequency $2000 \mathrm{~Hz}$ in this circuit done by simulation MATLAB for produce lower (THD) [6].

The harmonic elimination technique applies to multilevel inverter of seven and eleven level for elimination 3th, 5th and 3th, 5th and 7th respectively have been explanation in [7]. For optimization control have different type can be applied to multilevel inverter to optimized switching angle for capability of THD minimization. The optimization PSO and GA and HSA techniques have been used for computing switching angle via solved non-liner transcendental equation drive from selective harmonic elimination (SHE) for output voltage based on 7-level cascaded H-bridge multilevel inverter have been present in [8]. The (SHE) considered low-frequency technique in order to elimination 3th and 5th based on 7-level inverter with different modulation index (MI) equal to 0.65-1.0, the optimum harmonic reduction have been present in [9]. PSO algorithm implementation for decrease THD of CHB-MLI compare five and seven level, can be observe that THD for 7-level much better than 5-level inverter have been live in [10-12]. according to the conventional circuit using in CHB-MLI consist eight switching PWM for produce five level inverter and then twelve switching PWM for generate seven level inverters [12, 13]. The iteration solved number of switching angle by non-linear equation was achieve by PSO technique.

The optimization switching angle by PSO technique equal 3 angles based on 7-level inverter with reduce harmonic distortion 3th and 5th odd has monic order. NR and PSO have been achieve by excremental and simulation result [15]. The improvement of outpout voltage quality for both of symmetrical and asymmetrical MLI types of MLI, both are very effective and efficient to reduced the number of switching devices for conventional and non-conventional Hybrid MLI topologies to create a specified output stepped number of voltage levels with more effect operating and higher voltage levels based on DC voltage supply [16-18]. The ANN controller has been covered design, and analysis prototype of prediction to generate a real-time of optimal switching angles in a single-phase topology of modified five level CHB-MLI. The research proposal of a five-level modified cascaded H-bridge multilevel inverter (M-CHBMI) with artificial neural network (ANN) controller has been improve the output voltage and current performance and achieve a lower total harmonic distortion (THD). The study is designed the hardware of 5-level M-CHBMI using DSP-TMS320F2812 and to develop a proposed ANN controller algorithm for the 5-level CHBMI to achieve lower output voltage and current THD and improve the output voltage and current performance.

\section{PROPOSED A MODIFIED CIRCUIT OF FIVE-LEVEL CHB}

The harmonic components determined by using switching output voltage functions; therefore, the harmonics reduction is limited. At this research paper the amplitude of output voltage level are presented as five steeped as $\left((+\mathrm{V}) \_\mathrm{dc},+1 / 2 \mathrm{~V}\right.$ dc zero, $-1 / 2 \mathrm{~V}$ dc, and $\left.-\mathrm{V} \_\mathrm{dc}\right)$ and based on Table 1, the switching pattern of these output values are presented as shown in Figure 2. Vab at low switching frequency CHB-MLIs for 5-level as shown in Figure 3. Figure 1 are representing a topology of single-phase five-level inverter that have been proposed. By Increased the number of stepped levels of output waveform, a harmonic contents are reduced. It observed based on implement an auxiliary configuration of full-bridge circuit that formed by four diodes linked with middle switching device and dc capacitor bus voltage as half-level power supply.

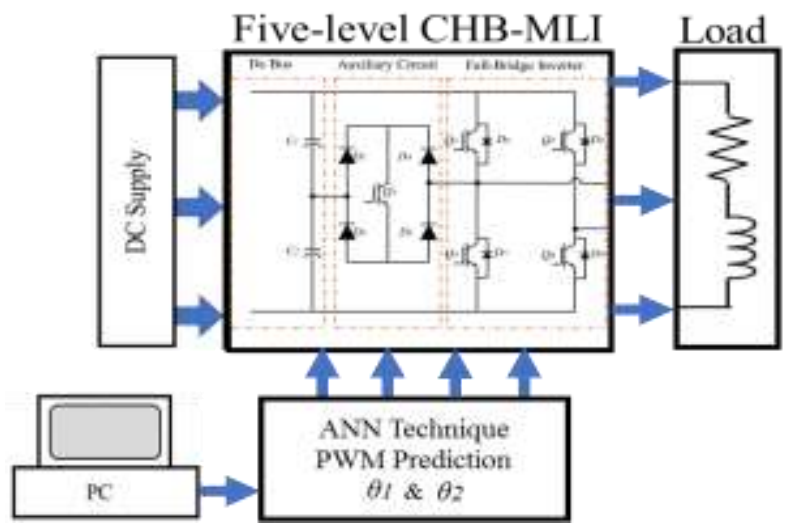

Figure 1. Proposal modified of a CHB-MLI, single phase five level topology 
Table 1. Output voltage for five level to the switches' on=1-off $=0$ condition

\begin{tabular}{ccccccc}
\hline State & S1 & S2 & S3 & S4 & S5 & Vo \\
\hline A & 1 & 0 & 0 & 1 & 0 & Vdc \\
B & 0 & 0 & 0 & 1 & 1 & $\mathrm{Vdc} / 2$ \\
C & 0 & 0 & 1 & 1 & 0 & 0 \\
D & 1 & 1 & 0 & 0 & 0 & $0 *$ \\
E & 0 & 1 & 0 & 0 & 1 & $-\mathrm{Vdc} / 2$ \\
F & 0 & 1 & 1 & 0 & 0 & $-\mathrm{Vdc}$ \\
\hline
\end{tabular}
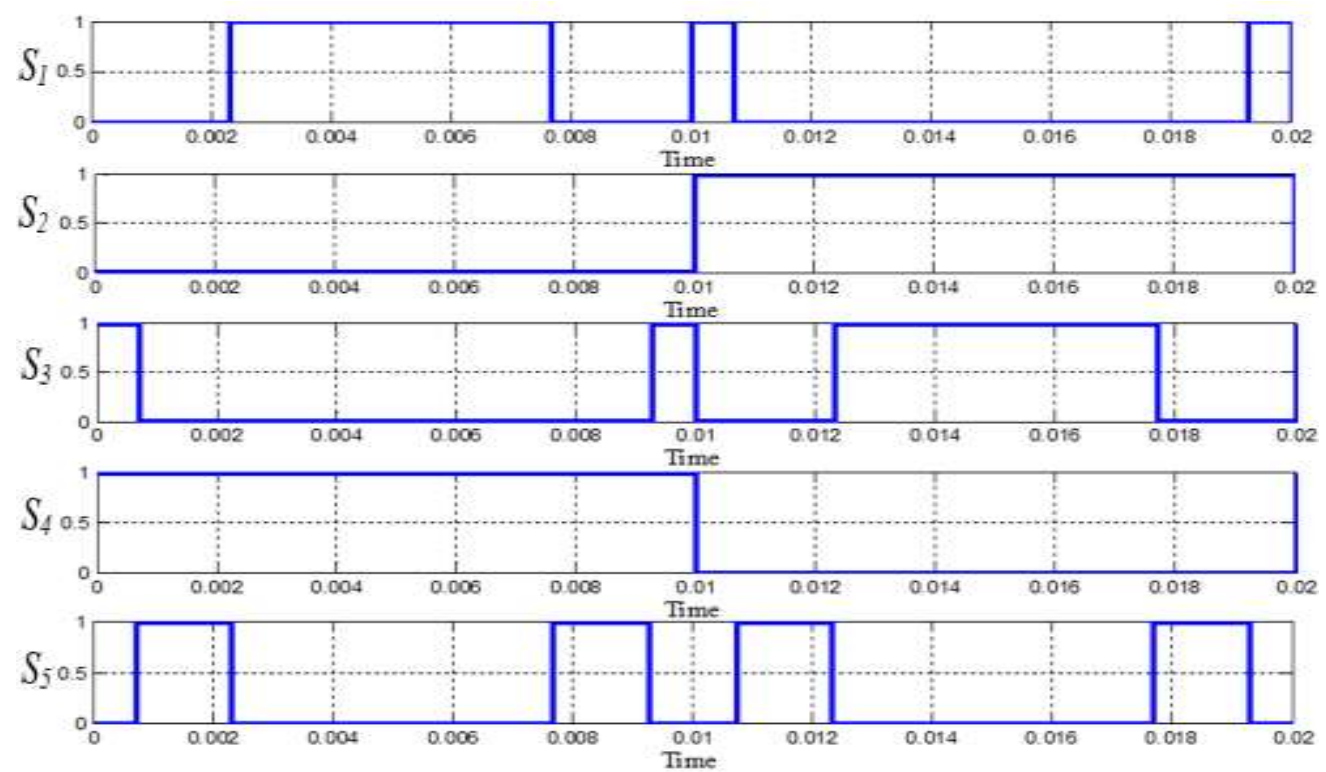

Figure 2. Switching pattern for 5-level modified of a CHB-MLI

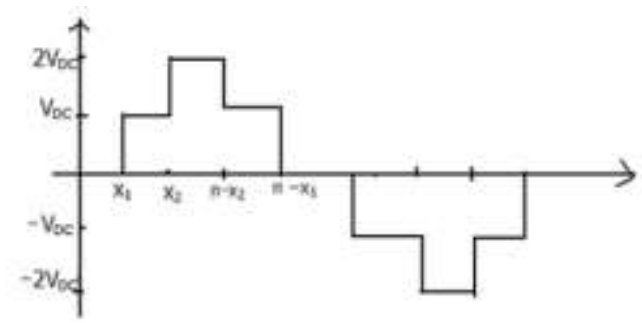

Figure 3. Vab at low switching frequency CHB-MLIs for 5-level

\section{FURRIER SERIES EQUATION}

According to 5-steeped waveform, the equations of FFTcan be described as: [19-21]:

$$
f(t)=f_{\theta 1}(t)+f_{\theta 2}(t) \sum_{n=1,2,5}^{\infty} \frac{2 V d c}{n \pi}\left(V_{d c 1} \cos \left(n \alpha_{1}\right)+V_{d c 2} \cos \left(n \alpha_{2}\right)\right) \sin (n w t)
$$

where:

Vdc: input voltage source that was in unity

$\theta i$ : variable switching angles group

From $\theta 2$ and $\theta 1$, four equations are resulted which eliminate a 5 th harmonic order.

$$
\begin{aligned}
& V_{A N}=V_{d c 1} \\
& b_{n}=\frac{2 V_{d c}}{\pi}\left\{\cos \left(n \alpha_{1}\right)+\cos \left(n \alpha_{2}\right)\right\} n=1,3,2
\end{aligned}
$$


(2) has s variables $\left(\theta_{1}, \theta_{2}\right)$, where $0<\theta_{1}<\theta_{2}<\pi / 2$, and a solution set is obtained by assigning a specific value to the fundamental component, $\mathrm{Vf}$, and equating s-1 harmonics to zero as given below:

$$
V_{1} \cos \left(\theta_{1}\right)+V_{2} \cos \left(\theta_{2}\right) 2 m \quad V_{1} \cos \left(3 \theta_{1}\right)+V_{2} \cos \left(3 \theta_{2}\right)=0
$$

where $\mathrm{m}=\mathrm{Vf} /(2 \mathrm{Vdc} / \pi)$, and it is related to the modulation index $\mathrm{mi}$ by $\mathrm{mi}=\mathrm{m} / \mathrm{s}$, where $0<\mathrm{mi}<1$. An objective function is then needed for the optimisation procedure selected as a measure of effectiveness of eliminating selected order of harmonics while maintaining the fundamental component at a pre-specified value. Therefore, this objective function is defined as: [22-25]

$$
\mathrm{F}\left(\theta_{1}, \theta_{2}, \ldots, \theta_{s}\right)=\left[\sum_{\mathrm{n}=1}^{\mathrm{s}} \mathrm{V}_{1} \cos \left(\theta_{\mathrm{n}}\right)-\mathrm{m}\right]^{2}+\left[\sum_{\mathrm{n}=1}^{\mathrm{s}} \mathrm{V}_{2} \cos \left(3 \theta_{\mathrm{n}}\right)\right]^{2}+\cdot\left[\sum_{\mathrm{n}=1}^{\mathrm{s}} \mathrm{V}_{\mathrm{s}} \cos (2 s-1) \theta_{\mathrm{s}}\right]^{2}
$$

The proper switching angles can be calculated by minimize (4) with condictional of $0<\theta_{1}<\theta_{2}<\pi / 2$, in which achieving a required harmonic contants. The main point of the transcendental set of non-linear (3), that most of iterative techniques can be used in order to acheve a spesifice switching angles as shown in Figure 4 and each step is explained below. By solving a non-linear transcendental equation with a modulation index both of angles $\theta_{1}$ and $\theta_{2}$, can be selected. a modulation index can be obtained be using formula (5).

$$
M=\frac{\pi \mathrm{V} f}{2 V_{d c}}(0 \leq M \leq 1)
$$

Where, $\mathrm{M}$ is the modulation index other switching angles form $\theta 3$ until $\theta 8$ can be obtained based on first and second switching angles $(\theta 1$ and $\theta 2)$ by indicate of a 5-levels output waveform of a modified CHB-MLIs as shown in Figure 3. The detection process of configuration and attributes system can be called as optimization procedure. only a 3 th harmonics order should be eliminated. Thus, by solve a transcendental equation using ANN technique, the switching angle can be found. the switching pattern of 5-levels inverter are turned on and turned off as its illustrated in Figure 2 with the accurate sequence to control and generate S1 until S8 in intent provide 5-level waveform of output voltage, based on a M-CHB-MLIs. These switching angles are calculated then detect and identical of THD that can be given by:

$$
T H D_{V}=\frac{\sqrt{\sum_{n=1}^{\infty} V_{n}^{2}}}{V_{1}}
$$

The expect switching angles ( $\alpha 1$ and $\alpha 2)$ of five-levels with the effected THD and modulation index is shown in Figure 3. Based in MATLAB code have been created according to sutible iteration number that can be easily detect a fundamental predicted switching angles for five-levels ( $\theta 1$ and $\theta 2$ ) based on $M=0.949$, However, resultant $\mathrm{THD}=14.48 \%$ for five-levels.

\section{ANN CONTROL TECHNIQUE}

ANN is a powerful tool to control a nonlinear system that is very complex in nature. A well-designed ANN can be used to replace the look up table and to generate optimal switching angles in a real-time manner [26].

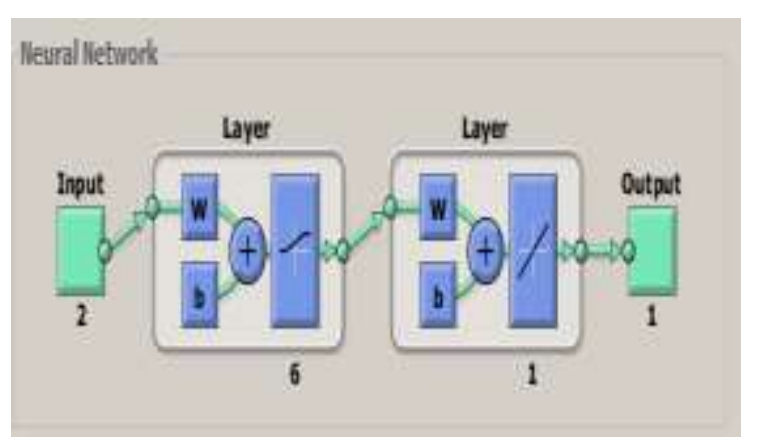

Figure 4. ANN controller block diagram 


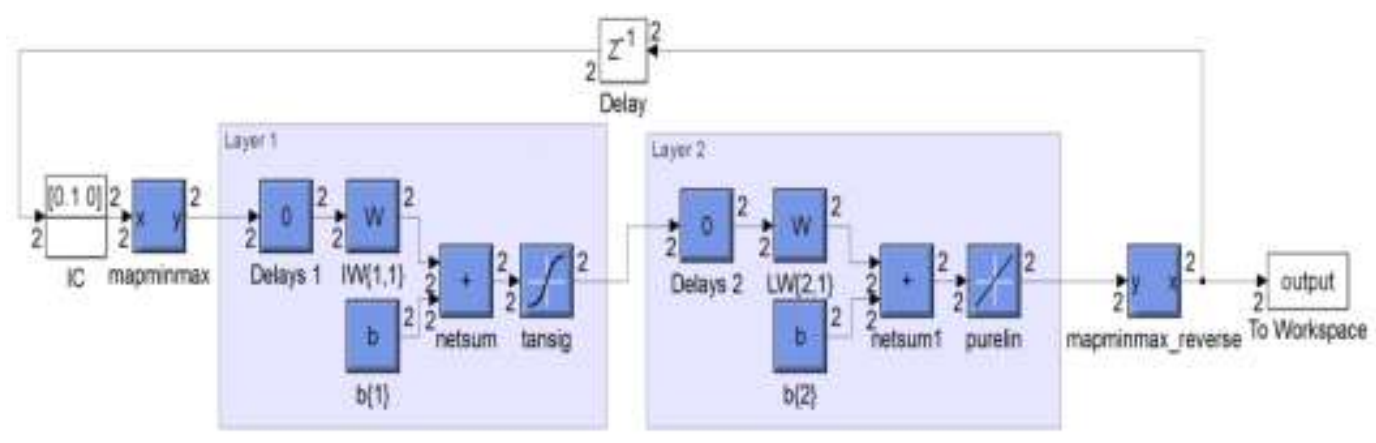

Figure 5. Simulink model for ANN-based henon map chaotic system

The ANN architecture is illustrated by Figure 4, including an input layer with two inputs, a hidden layer with two hidden neurons, and an output layer with two outputs. A simulink Model is created using the ANN with delayed feed-back loop as shown in Figure 5. A typical two-layer feed-forward network shown in Figure 6 with sigmoid hidden neurons and linear output neurons can fit multidimensional mapping problems arbitrarily well. There are $n$ inputs and vectors $P$ in an input layer, $t_{1}$ sigmoid hidden neurons in hidden layer, and $t_{2}$ linear output neurons in output layer. ANN controller network structure is defined based on the number of neurons in the input layer, hidden layer and output layer respectively. The first neuron of the output layer is used as input to feed the PWM generator to generate switching signal for the proposed M-CHBMI. The connections weight parameter between jth and ith neuron at mth layer is given by wmij, while bias parameter of this layer at ith neuron is given by bmi. Transfer function of the network at ith neuron in mth layer is defined by:

$$
n_{i}^{m}=\sum_{j=1}^{s^{m-1}} W_{i j}^{m} a_{j}^{m-1}+b_{i}^{m}
$$

The output function of neuron at mth layer is given by:

$$
a_{i}^{m}=f^{m}\left(n_{i}^{m}\right)
$$

where $f$ is activation function of the neuron. In this design the activation function of the output layer is unity and for the hidden layer is a tangent hyperbolic function given by:

$$
f^{m}\left(n_{i}^{m}\right)=\frac{2}{1+e^{-2 n_{i}^{m}}}-1
$$

Appling ANN to the harmonic minimization problem described in above section, the procedure is presented in Figure 7, and the results of optimal switching angles are presented in Figure 6.

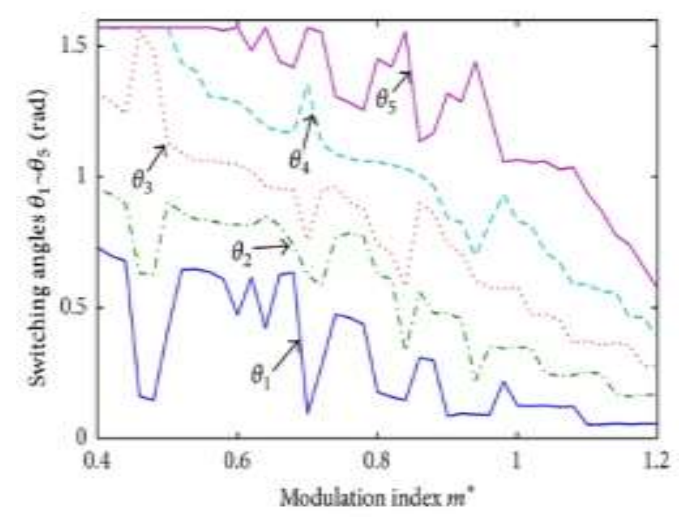

Figure 6. Calculated switching angles $\theta_{1}$ and $\theta_{2}$ 


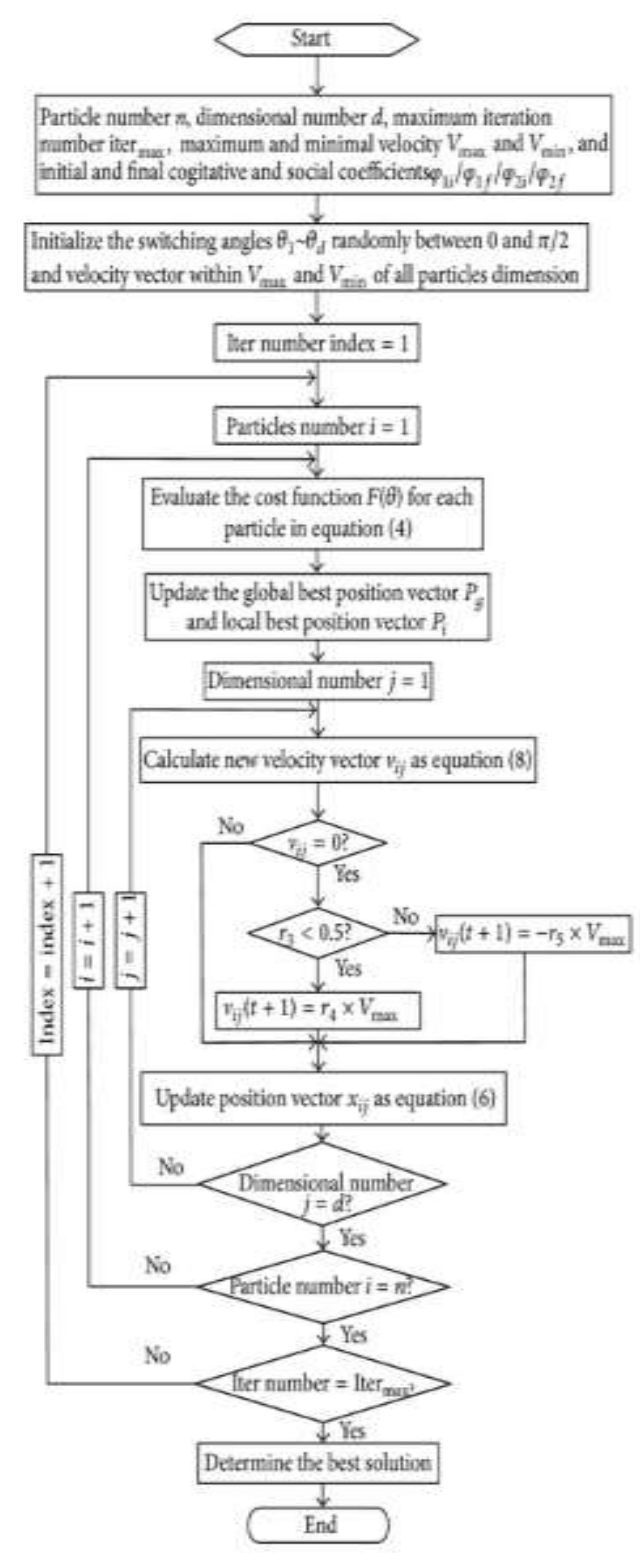

Figure 7. Flow chart of ANN applying to harmonic minimazation problem

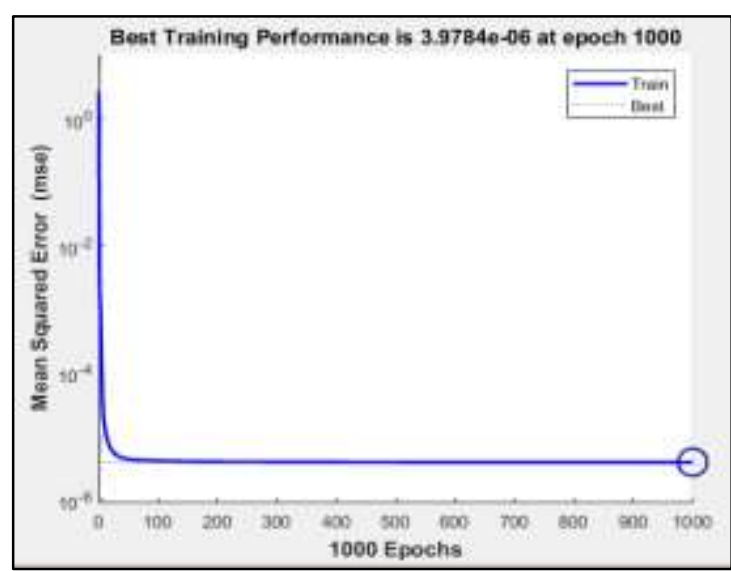

Figure 8a. ANN training performance with 2 hidden neurons

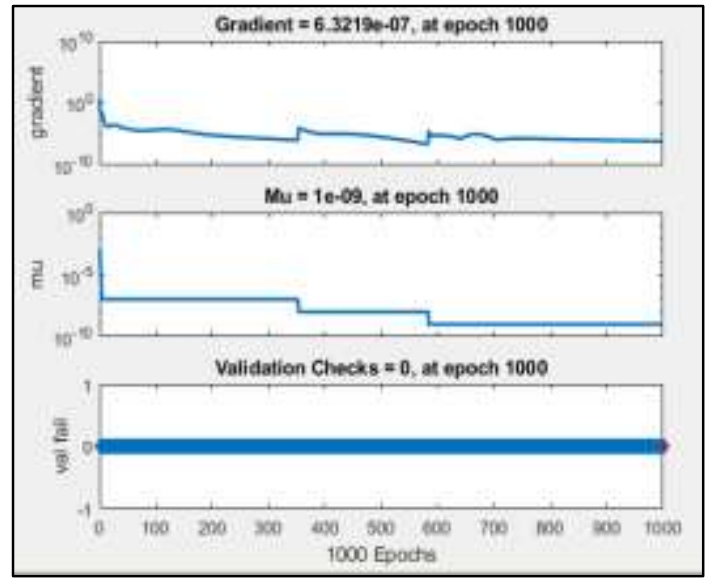

Figure 8 b. ANN training performance with 2 hidden neurons 


\section{THE HARDWARE OF MODIFIED FIVE LEVELS CHB-MLI}

The hardware of single phase of modified five-level CHB-MLIs has been performing for switching frequency value of $2500 \mathrm{~Hz}$. With single-phase passive load as $20 \Omega$, and $5 \mathrm{mH}$. Supplied by dc voltage as $300 \mathrm{~V}$.also at this prototype system, each cycle was containing $0.02 \mathrm{~s}$ as duration time. the switching angles have been calculated with ANNs technique in which $\mathrm{Q} 1=11.54$ and $\mathrm{Q} 2=39.21$ with $\mathrm{M}=0.949$ for five levels single-phase modified CHB-MLIs. In Figure 9, as can be observed of predicted data and original data for the THD with test values.

The training set is used for computing the gradient and updating the network weight and bias values. The validation set is used to monitor the error during training process in order to avoid overfitting. The test set is used to test the training performance Training: $\mathrm{R}=0.99995 \mathrm{as}$ shown in Figure 10. A modified five-levels CHB-MLI build by merge and involves five devices of power semiconductor IGBTs-IHW30N90T with snubber circuits, as shown in Figure 11. The operating switching frequency of IGBT have been procesed with capability of up to $100 \mathrm{kHz}$ and $60 \mathrm{~A}$ as electric current supply when a temperature of switching device is $25^{\circ} \mathrm{C}$, and becoming $30 \mathrm{~A}$ when temperature reached to $100^{\circ} \mathrm{C}$.

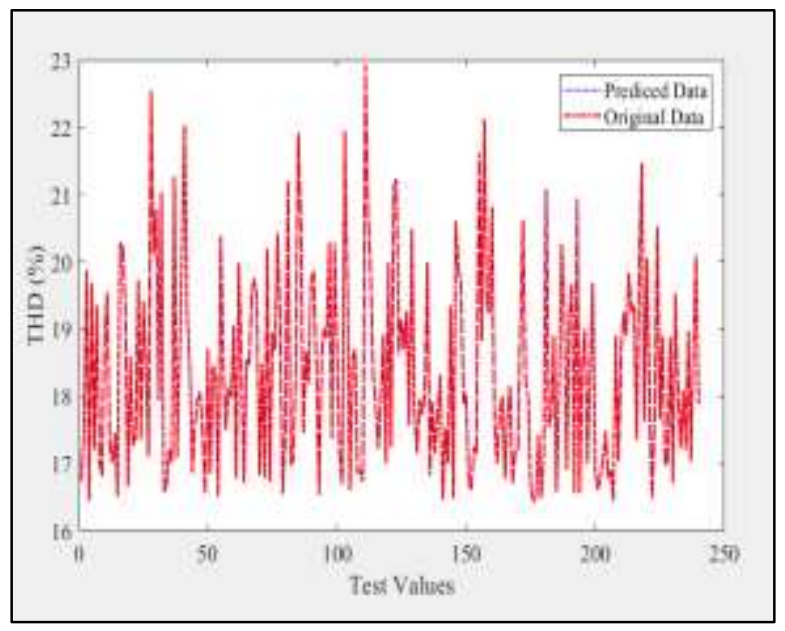

Figure 9. Predicted data and original data for THD

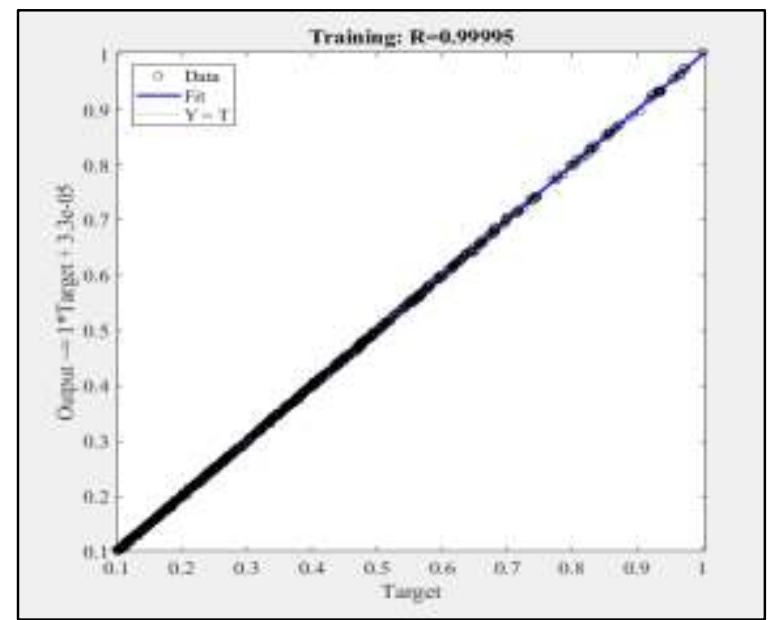

Figure 10. Training performance angles for ANN

Normally, it can operate at 600-volt DC towards the break down voltage at 900-volt DC. These IGBTs can accept a maximum of $\pm 30 \mathrm{~V}$ gate to emitter voltage pulse. More information pertaining to this IGBT-IHW30N90T. Besides, the single-phase switching signal to those IGBTs came from the gate drives circuits. The important aspects in the selection of IGBT had been the voltage of the IGBT collector to emitter. If the output phase voltage inverter designed had been 300 volts AC (peak to peak), then a voltage source DC at $\sqrt{2} \times 300 \mathrm{~V}$ or 424.27 volt DC would be needed to avoid break down voltage on IGBTs as the inverter output was loaded with resistance and inductance. Besides, the switching sequence of the voltage across IGBT had been similar to the voltage DC source. Another aspect was the electric current capacity that allowed flow through the IGBTs. This means that if the inverter was designed to drive the motor with high current, then IGBT with high current should be chosen due to its ability in conducting frequency switching. With high-frequency capability of IGBTs, then high switching frequency, instead of low switching, could be applied on single-phase five-level of a modified CHB-MLIs so that it could produce output with less harmonics.

\section{OPTIMIZATION EXPERIMENTAL RESULTS OF A SINGLE PHASE OF FIVE LEVEL MODIFIED CHB MLIS (MI=0.949)BASED ON ANN AND PSO TECHNIQUES}

In the case of mitigation of THD in a modified CHB-MLIs inverter, the SHE-PWM switching method is used to calculate the values of switching angles from the solution of non-linear transcendental equations. These non-linear complex equations are minimised by using the ANN and PSO techniques. In order to determine if both of simulation results and experimental results are in good agreement with each othe. A source code based on the ANN and PSO techniques for the optimisation of a single-phase modified CHB-MLIs has been developed. 


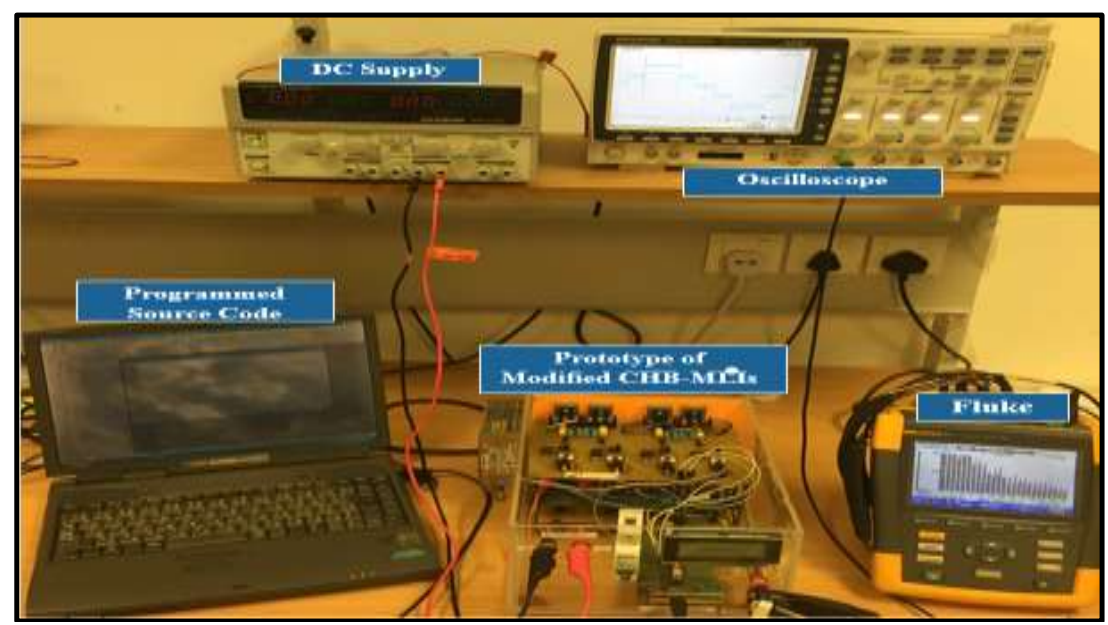

Figure 11. The development of a single-phase of modified CHB-MLIs for five-levels

The developed source code programming was then stored into DSP-TMS320F2812. The DSP-TMS320F2812 card was then interfaced with the modified prototype for single-phase CHB-MLI scheme that proposed. In the source code programming, one cycle consists of the duration of $0.02 \mathrm{~s}$ with $\mathrm{MI}=0.949$. Meanwhile, the values of the switching angles were calculated using the PSO technique and the obtained values are $\theta_{1}=13.41$ and $\theta_{2}=41.93$. by using PSO technique as controller of a proposed single-phase modified CHB-MLIs comprises switches S1, S2, S3, and S4 and S5 as bi- directional switch as illustrated in Figure 12. The optimised output waveform for both of voltage and current in a single-phase five-levels modified CHB-MLIs using the PSO technique are shows in Figure 13. While both of Figure 14 and Figure 15 shows the spectrum of optimised harmonic during output waveform of voltage and current in a single-phase five-level modified CHB-MLIs in which ratio of THD accomplished to $15.3 \%$ and $8.2 \%$ respectively by using the PSO technique. In the next experiment, a prototype of a modified five-level CHBMLIs is verified with ANN technique. By using the same models of PSO technique, the switching angles for optimisation are calculated using the ANN technique.

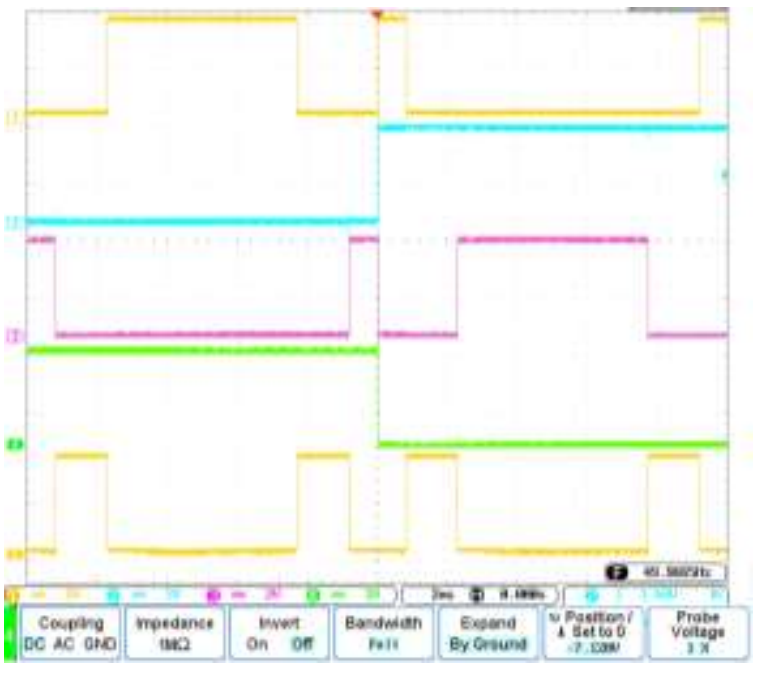

Figure 12. Timing diagram of a five-level modified CHB-MLIs comprising switches $\mathrm{S}_{1}, \mathrm{~S}_{2}, \mathrm{~S}_{3}$, and $\mathrm{S}_{4}$ and bidirectional switch $\mathrm{S}_{5}$ with $\mathrm{MI}=0.949$ using PSO technique

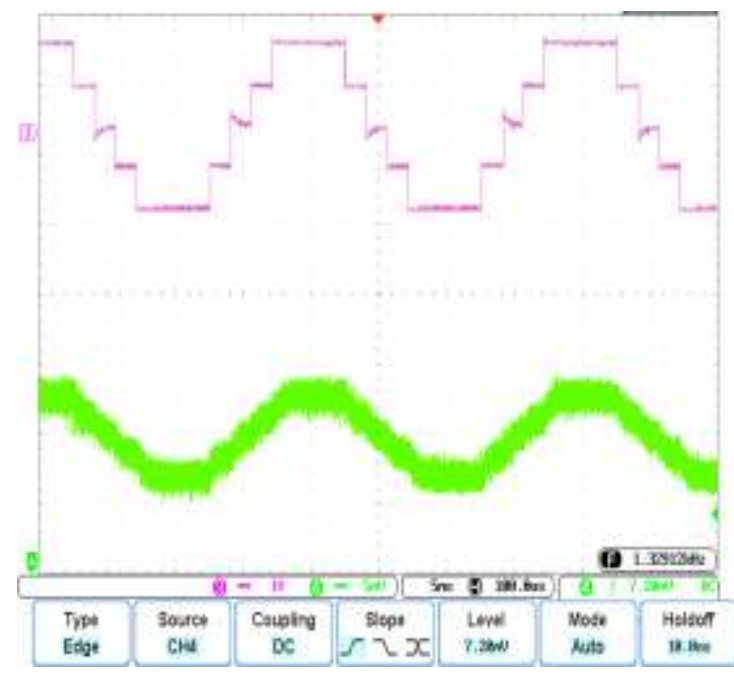

Figure 13. Optimisation of output voltage and current waveform of a five-level CHB-MLIs with MI-0.949 using PSO technique 


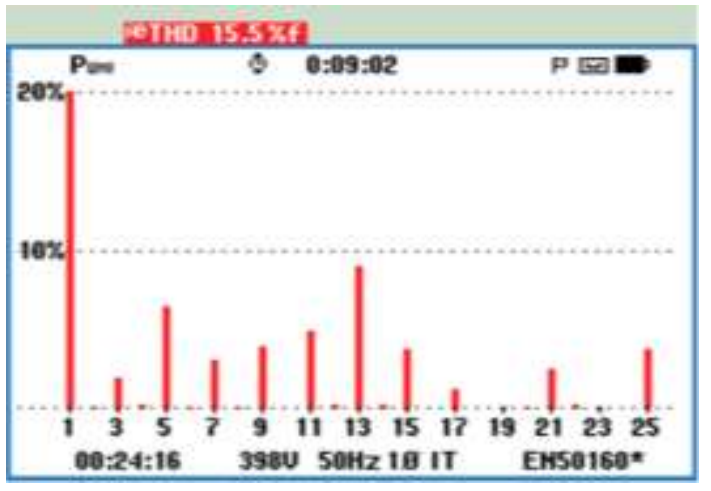

Figure 14. Harmonic spectrum of the optimization of single-phase output voltage waveform using PSO technique

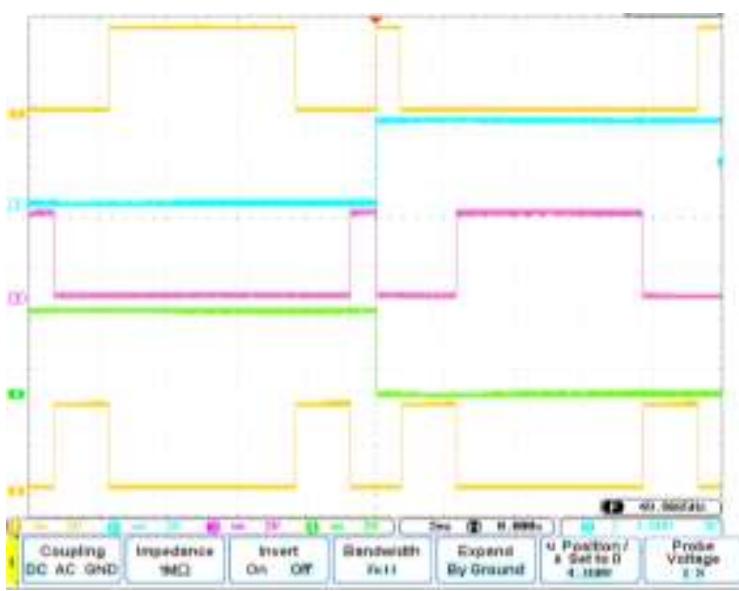

Figure 16. Timing diagram of a modified CHB-MLIs comprising switches $\mathrm{S}_{1}, \mathrm{~S}_{2}, \mathrm{~S}_{3}$, and $\mathrm{S}_{4}$ and bidirectional switch $S_{5}$, with $\mathrm{MI}=0.949$ using ANN technique

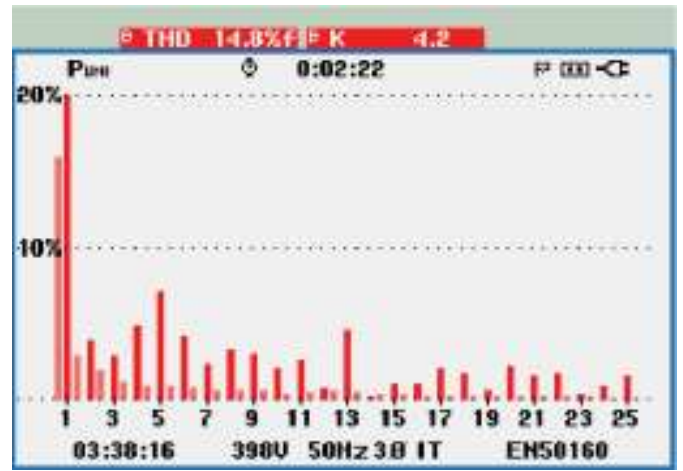

Figure 18. Optimisation harmonic spectrum of a single-phase output voltage waveform using ANN technique

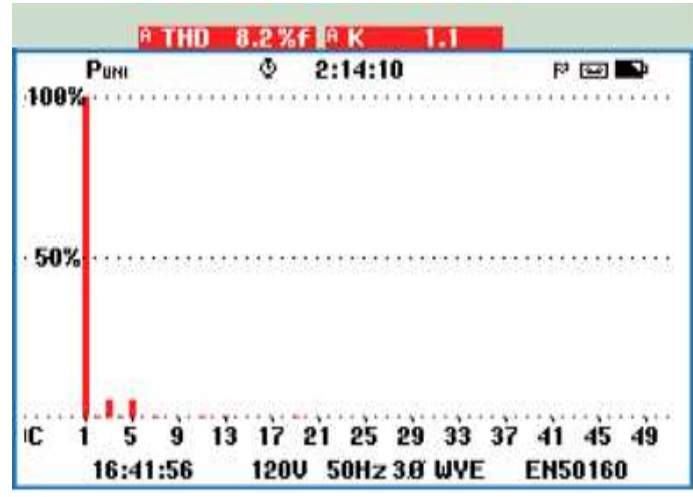

Figure 15. Harmonic spectrum of a single-phase output current waveform using PSO technique

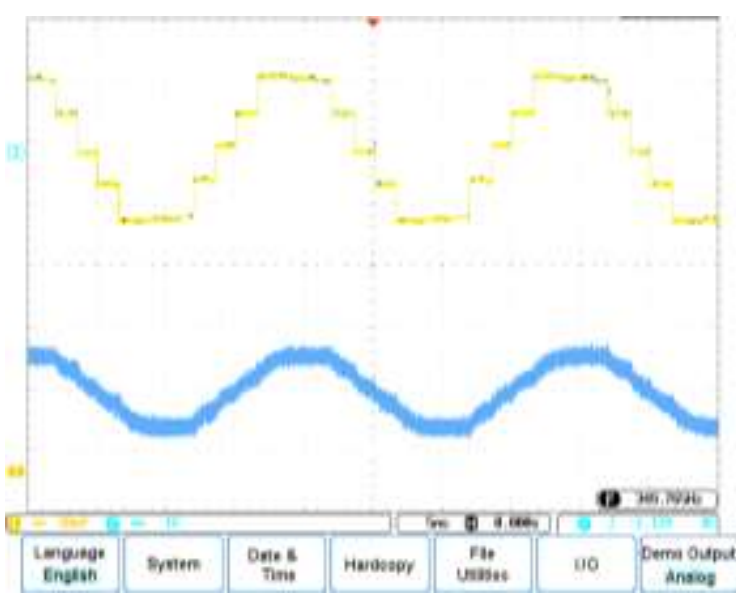

Figure 17. Optimisation of output voltage and current waveform of a five-level CHB-MLIs with $\mathrm{MI}=0.949$ using ANN technique

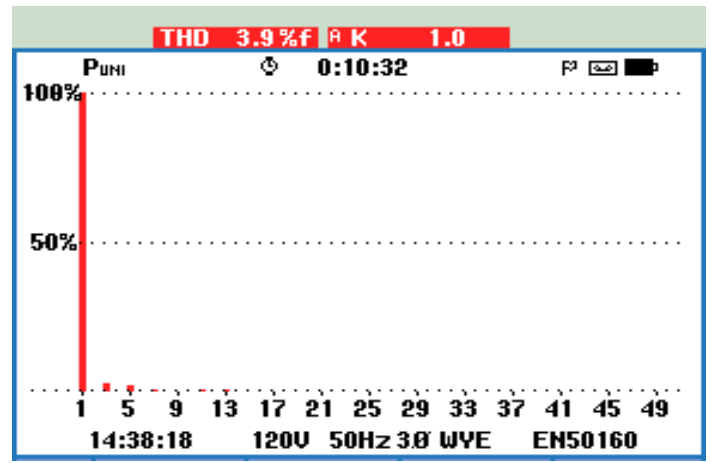

Figure 19. Optimisation harmonic spectrum of a single-phase output current waveform using ANN technique

The switching angles have been calculated with ANNs which obtained is $\theta_{1}=11.54$ and $\theta_{2}=39.21$. Figure 16 shows the timing diagram of switch pulses and bi-directional switch of a single-phase five-level 
modified CHB-MLIs using the ANN technique. The pattern of switching time diagram of a modified five-level CHB-MLIs using the ANN technique is almost similar with the PSO technique, however, the method to obtain the switching angle calculation using the ANN technique is quite different as compared to using technique of PSO.

The optimised output waveform for both of voltage and current in a five-levels modified CHB-MLIs using the ANN technique are shown in Figure 17 while Figure 18 shows shows the spectrum of optimised harmonic during output waveform of voltage in a modified single-phase five-level CHB-MLIs in which ratio of THD accomplished to $14.48 \%$ using ANN. Based on a timing diagram that referred in Figure 16 the optimised of both of voltage and current output waveform" for a single-phase modified five levels CHB-MLIs using ANN can be shown in Figure 17. The output voltage waveform is smoother when using the ANN technique. Both of Figure 18 and Figure 19 shows the spectrum of optimised harmonic during output waveform of voltage and current waveform in a modified single-phase five-level CHB-MLIs in which ratio of THD accomplished to $14.48 \%$ and $3.9 \%$ respectively by using the ANN technique. As shown bellow values of MI, switching angles and THD for voltage of modified CHB-MLI for five-levels based on proposal ANN and PSO techniques. Figure 20 shows the plotting output for switching angles and the THD values for voltage based on proposal ANN and PSO techniques.

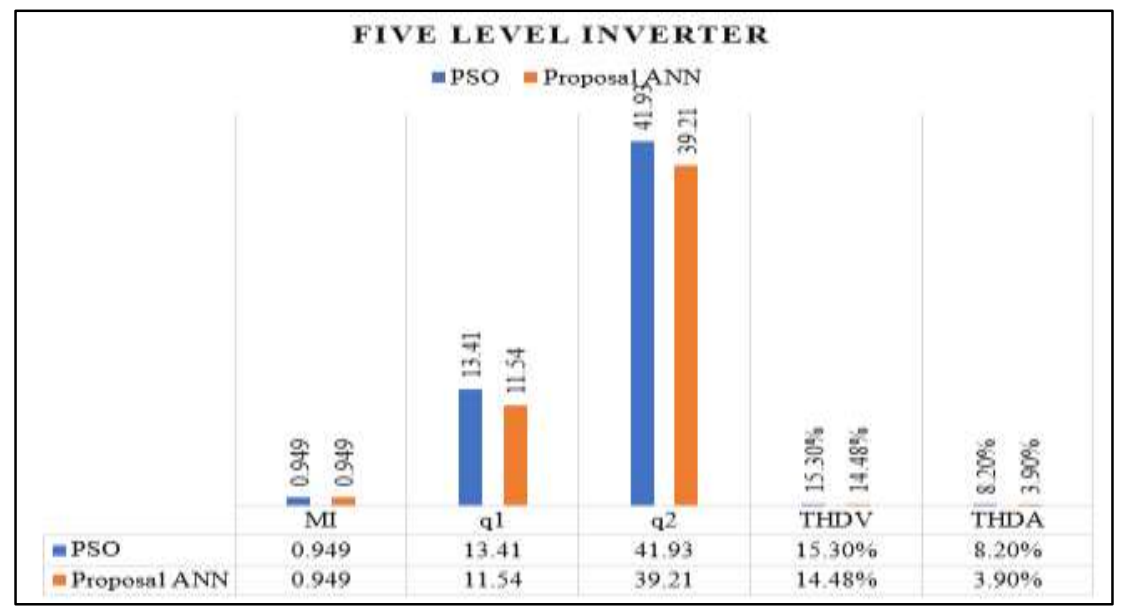

Figure 20. Values for each switching angle and the of voltage and current THD values of five-levels M-CHBMLI based on ANN and PSO techniques

\section{CONCLUSION}

This paper has provided analysis of accuracy performance in ANN results showed that produce lower value of switching angles also an ANN technique simpler and more efficient than PSO technique. The final result that have been show up in results are indicating for that the harmonics contents are reduced by increased levels of modified CHB-MLI inverter. And ANNs control have been achieved lower THD at output waveform of voltage and current. However, ANN technique provides lower THD content at output waveform of voltage and current in a modifieds CHB-MLI as compare with PSO technique.

\section{ACKNOWLEDGEMENTS}

This research is sponsored by the grant Penyelidikan Jangka Pendek (PJP) which the number is PJP/2019/FKE(2A)/S01668. The authors would also like to thank the Centre for Research and Innovation Management Universiti Teknikal Malaysia Melaka (CRIM-UTeM) for the funding to support this project to providing the facilities and research environment.

\section{REFERENCES}

[1] M. Rasheed, R. Omar, M. Sulaiman, and W. A. Halim, "Particle swarm optimisation (PSO) algorithm with reduced numberof switches in multilevel inverter (MLI)," Indones. J. Electr. Eng. Comput. Sci., vol. 14, no. 3, pp. 1114-1124, 2019, doi: 10.11591/ijeecs.v14.i3.pp1114-1124.

[2] R. Omar, T. Z. Hao, M. Rasheed, and M. Sulaiman, "An Improvement of Shunt Active Power Filter using Effective Controller for Different Load Condition,” J. Eng. Appl. Sci., vol. 15, no. 6, pp. 1311-1321, 2020. 
[3] M. Rasheed, R. Omar, and M. Sulaiman, "Optimization switching angle based on practical swarm optimization (PSO) of A DSP-TMS320F2812 controlled for multilevel inverter," Int. J. Eng. Technol., vol. 7, no. 4, pp. 5666-5672, 2018.

[4] M. S. and W. A. H. Rosli Omar, Mohammed Rasheed, Nizam Mies, The Performance of the Modified Cascaded HBridge Multilevel Inverters (CHB MLIS) with Various Modulation Index (MI) using Firefly Algorithm, 2019.

[5] S. Salleh, et al., "Review On Modeling and Controller Design in Pneumatic Actuator Control System," Int. J. Smart Sens. Intell. Syst., vol. 8, no. 1, pp. 338-367, 2015. https://doi.org/10.21307/ijssis-2017-762.

[6] V. N. B. Reddy and V. Narasimhulu, Dr. Ch. Sai Babu, "Control of Cascaded Multilevel Inverter By Using Carrier Based Pwm Technique and Implemented To," ICGST ACSE Journal, vol. 10, no. 1, pp. 11-18, 2010.

[7] A. Parkash, S. L. Shimi, and S. Chatterji, "Harmonics Reduction in Cascade H-Bridge Multilevel Inverters Using GA and PSO," International Journal of Engineering Trends and Technology (IJETT), vol. 12, no. 9, pp. 453-465, 2014.

[8] I. Colak and E. Kabalci, "Developing a novel sinusoidal pulse width modulation (SPWM) technique to eliminate side band harmonics," Int. J. Electr. Power Energy Syst., vol. 44, no. 1, pp. 861-871, Jan. 2013. doi: 10.1016/j.ijepes.2012.08.024.

[9] B. Xiao, et al., "Control of cascaded H-bridge multilevel inverter with individual MPPT for grid-connected photovoltaic generators," 2012 IEEE Energy Conversion Congress and Exposition (ECCE), Raleigh, NC, pp. 3715-3721, 2012. doi: 10.1109/ECCE.2012.6342474.

[10] D. Subramanian and R. Rasheed, "Nine-Level Cascaded H-Bridge Multilevel Inverter," International Journal of Engineering and Innovative Technology (IJEIT), vol. 3, no. 3, pp. 201-205, 2013.

[11] D. C. Symposium, et al., "ScienceDirect ScienceDirect Hybrid multilevel DC link inverter with reduced power electronic Heating power and Cooling Hybrid multilevel with reduced electronic switches switches Assessing the feasibility of using b the Jegathesan V district function for," vol. 00, pp. 1-9, 2017.

[12] T. Demirdelen, R. I. Kayaalp, and M. Tumay, "Simulation Modelling Practice and Theory Simulation modelling and analysis of modular cascaded multilevel converter based shunt hybrid active power filter for large scale photovoltaic system interconnection," Simul. Model. Pract. Theory, vol. 71, pp. 27-44, 2017. doi: 10.1016/j.simpat.2016.11.003.

[13] N. Bodo, E. Levi and M. Jones, "Investigation of Carrier-Based PWM Techniques for a Five-Phase Open-End Winding Drive Topology," in IEEE Transactions on Industrial Electronics, vol. 60, no. 5, pp. 2054-2065, May 2013. doi: 10.1109/TIE.2012.2196013.

[14] S. H. Hosseini, M. Ahmadi and S. Ghassem Zadeh, "Reducing the output harmonics of cascaded H-bridge multilevel inverter for Electric Vehicle applications," The 8th Electrical Engineering/ Electronics, Computer, Telecommunications and Information Technology (ECTI) Association of Thailand - Conference 2011, Khon Kaen, pp. 752-755, 2011.

[15] J. J. Nedumgatt, D. V. Kumar, A. Kirubakaran and S. Umashankar, "A multilevel inverter with reduced number of switches," 2012 IEEE Students' Conference on Electrical, Electronics and Computer Science, Bhopal, pp. 1-4, 2012. doi: 10.1109/SCEECS.2012.6184819.

[16] R. A. Ahmed, S. Mekhilef and H. W. Ping, "New multilevel inverter topology with minimum number of switches," TENCON 2010 - 2010 IEEE Region 10 Conference, Fukuoka, 2010, pp. 1862-1867. doi: 10.1109/TENCON.2010.5686368

[17] S. S. Mohammed, R. B. Omar, M. Sulaiman, and M. Rasheed, "Aggregated modelling analysis of power flow from wind power plant into grid system using MATLAB/ Simulink software," ARPN J. Eng. Appl. Sci., vol. 13, no. 4, pp. 1163-1172, 2018.

[18] M. Rasheed, R. Omar, M. Sulaiman, and W. Abd Halim, "A modified cascaded h-bridge multilevel inverter based on particle swarm optimisation (PSO) technique,” Indones. J. Electr. Eng. Comput. Sci., vol. 16, no. 1, p. 41, 2019, doi: 10.11591/ijeecs.v16.i1.pp41-51.

[19] R. Vijayakumar, et al., "Selective Harmonic Elimination PWM Method using Seven Level Inverters by Genetic Algorithm Optimization Technique," Int. J. Eng. Res. Technol.(IJERT), vol. 4, no. 02, pp. 812-818, 2015.

[20] J. Rodríguez et al., "Multilevel Voltage-Source-Converter Topologies for Industrial Medium-Voltage Drives," IEEE Trans. Ind. Electron., vol. 54, no. 6, pp. 2930-2945, 2007.

[21] S. Francisco, V. Tipsuwanporn, W. Sawaengsinkasikit, and A. Numsomran, "3 Phase Induction Motor Controlled with," World Congr. Eng. Comput. Sci., vol. I, pp. 2-6, 2011.

[22] R. G. Omar, "Modified FCS-MPC algorithm for five-leg voltage source inverter," Indones. J. Electr. Eng. Comput. Sci., vol. 19, no. 1, pp. 47-57, 2020, doi: 10.11591/ijeecs.v19.i1.pp47-57.

[23] H. Sardar Kamil, D. M. Said, M. W. Mustafa, M. R. Miveh, and N. Ahmad, "Recent advances in phase-locked loop based synchronization methods for inverter-based renewable energy sources," Indones. J. Electr. Eng. Comput. Sci., vol. 18, no. 1, p. 1-8, , 2020, doi: 10.11591/ijeecs.v18.i1.pp1-8.

[24] J. Sabarad and G. H. Kulkarni, "Novel switching technique for five leg inverter in dual motor control," Indones. J. Electr. Eng. Comput. Sci, vol. 19, no. 2, pp. 644-651, 2020, doi: 10.11591/ijeecs.v19.i2.pp644-651.

[25] H. A. Mohamed and H. M. D. Habbi, "Power quality of dual two-level inverter fed open end winding induction motor," Indones. J. Electr. Eng. Comput. Sci., vol. 18, no. 2, pp. 688-697, 2020, doi: 10.11591/ijeecs.v18.i2.pp688697.

[26] L. Zhang, "Design and Implementation of Neural Network Based Chaotic System Model for the Dynamical Control of Brain Stimulation," Second Int. Conf. Neurosci. Cogn. Brain Inf., pp. 14-21, 2017. 